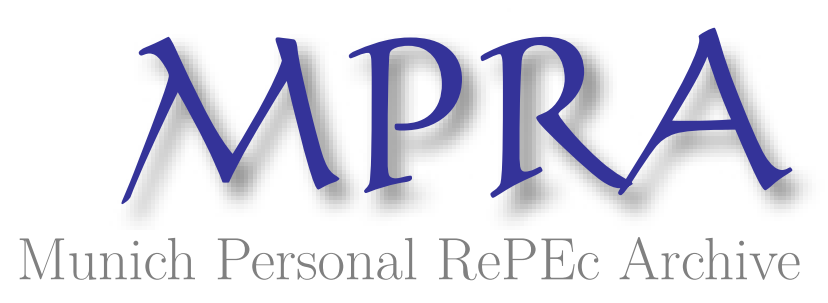

\title{
The Relationship Between Votes and Seats
}

Borooah, Vani

University of Ulster

December 2014

Online at https://mpra.ub.uni-muenchen.de/76619/

MPRA Paper No. 76619, posted 07 Feb 2017 13:50 UTC 


\section{Chapter 6 \\ The Relationship between Votes and Seats}

\subsection{Introduction}

As noted earlier, in Lok Sabha elections, a single representative for each of 543 constituencies is elected - on the basis of obtaining the largest number of votes of all the candidates contesting that constituency - as a Member of the Lok Sabha for that constituency. This system of election is called the First-Past-the-Post (FPTP) system. The disjoint, under this system, between the votes obtained and the seats won by a party frequently causes consternation. Unlike a proportional electoral system, in which a party's share of the total vote is a good predictor of its share of parliamentary seats, the relation between seats and votes in a FPTP system often works in mysterious ways.

For example, in the Lok Sabha elections of 2014, the Bharatiya Janata Party (BJP) won 282 seats with 31 percent of the vote while the INC with nearly 20 percent of the vote could manage only 44 seats; in the same election, the All India Anna Dravida Munnetra Kazhagam (AIADMK) won 37 seats with just 3.3 percent of the vote. Nor is this anomaly between votes and seats confined to India: in the UK General Election of May 2015, the Scottish National Party won 56 seats in the House of Commons on the back of just under 1.5 million votes while, in the same election, the UK Independence Party received nearly 4 million votes and were rewarded with just one seat.

In this chapter we attempt to understand some of these mysteries in respect of General Parliamentary Elections in India. This chapter is concerned with analysing the fortunes of India's two largest political parties, the Indian National Congress (INC) and the Bharatiya Janata Party (BJP) and in the context of the above remarks this chapter examines, in some detail, the relationship between the votes obtained and the seats won by the INC and the BJP.

The starting point of the analysis is the Law of the Cubic Proportion according to which, in a two-party contest, "the proportion of seats won by the victorious party varies as the cube of the proportion of votes cast for that party in the country as a whole" (Kendall and Stuart (1950) p. 183). ${ }^{1}$ In this chapter we take a different approach to this 'law' by separately computing for the INC and BJP

\footnotetext{
${ }^{1}$ Kendall and Stuart (1950) draw attention to the fact that the law was first proposed by James Parker Smith who, in turn attributed it to P.A. MacMahon - in evidence before the Royal Commission on Systems of Elections (2010).
} 
the coefficient which equates the proportion of their votes to the proportion of their seats. We term this the amplification coefficient and show that its value is very different for the two parties. Since the BJP gained political traction only from the 1989 General Election - when it won 85 seats, having won just two seats in the previous General Election of 1984 - the analysis in this chapter is confined to eight General Elections: 1989, 1991, 1996, 1998, 1999, 2004, 2009, and 2014.

\subsection{The Electoral Fortunes of the INC and the BJP}

Table 6.1 presents a summary account of election outcomes for the INC and the BJP for the eight Indian Lok Sabha elections held between 1989 and 2014. This highlights two features of the electoral performance of the INC and the BJP. First, the BJP always contested fewer seats than the INC though, with the INC's acceptance of the exigencies of seat adjustment under coalition government, the number of seats it contested fell from a high of 526 in 1996 (97\% of the total of 543 Lok Sabha seats) to a low of 417 in 2004 (77\% of Lok Sabha seats). Second, except for the 2009 and 1991 elections, when it won over 200 seats, the INC has always paid a higher "price" in terms of votes for the seats that it did win: for example, in 2004, when both parties won roughly the same number of seats - 145 for the INC to the BJP's 138 - the votes-per-seat for the INC, at 713,165, was considerably higher than the BJP's 625,881.

$<$ Table 6.1>

The corollary is that, compared to the BJP, the INC is relatively inefficient in terms of converting votes into seats: in 2004 , it won $26.5 \%$ of the vote compared to the BJP's $22.2 \%$ but only won seven more seats on the strength of this four point advantage; in 1996, it obtained a larger vote share (28.8\% compared to $20.3 \%$ ) but won fewer seats (139 compared to the BJP's 161); and in 1998, the BJP won 41 more seats than the INC (182 compared to 141) with the same share of the vote as the INC $(26 \%)$.

$<$ Table 6.2>

Given our interest in the two leading protagonists, the INC and the BJP, the focus of the analysis was those constituencies in which there was an INC and/or a BJP candidate so that constituencies in which there was neither an INC nor a BJP candidate were excluded from the analysis. Table 6.2 shows that of the total of 4,323 constituencies in the eight Lok Sabha elections 
between 1989 and 2014 there were only 245 constituencies which neither party contested (5.7 percent of the total) and 2,837 constituencies which were contested by both parties ( 65.6 percent of the total). ${ }^{2}$

\subsection{The 'Amplification Coefficient' and the Law of the Cubic Proportion}

We assume a two-party system (parties A and B), in which the representative in each constituency is elected under a 'first-past-the-post' (FPTP) system. Let $V_{A}^{t}$ and $V_{B}^{t}$ represent the votes obtained, and $S_{A}^{t}$ and $S_{B}^{t}$ won, by parties A and B, respectively, at an election held in time $t$ such that $V_{A}^{t}<V_{B}^{t}$. If $\left(V_{A}^{t} / V_{B}^{t}\right)<1$ is the ratio of votes accruing to parties $\mathrm{A}$ and $\mathrm{B}$, then for some real number $\alpha$, we must have:

$$
\left(\frac{V_{A}^{t}}{V_{B}^{t}}\right)^{\alpha}=\frac{S_{A}^{t}}{S_{B}^{t}}
$$

We refer to the term $\alpha$ as the amplification coefficient because it amplifies the votes ratio into a seats ratio. For example, if $\alpha=3$ and the vote ratio is $40 / 60$ (that is, $1: 1.5$ meaning that for every vote obtained by party A, party B obtains 1.5 votes), then the seats ratio will be $(40)^{3} /(60)^{3}$, that is $1: 3.4$, meaning that for every seat won by party A, party B would win 3.4 seats. So, if there were 100 seats contested, parties A and B would win 23 and 77 seats, respectively. ${ }^{3}$

The value $\alpha=3$ embodies the 'Law of the Cubic Proportion' of election results under a FPTP system (Kendall and Stuart, 1951; Rajagopalan, 1959; Curtice and Steed, 1986; Norris and Crewe, 1994). In general, of course, the value of $\alpha$ will be different from 3 . Indeed, for any given election, it is possible to solve for, $\alpha$, the amplification coefficient associated with that election as:

$$
\alpha=\frac{\log \left(S_{A}^{t} / S_{B}^{t}\right)}{\log \left(V_{A}^{t} / V_{B}^{t}\right)}
$$

Various values of $\alpha$ are possible:

\footnotetext{
${ }^{2}$ Bear in mind that 'observations' were distinguished by constituency name and by election year: so, for example, Adilabad in the 1989 Lok Sabha election represented a separate observation from Adilabad in the 1991 Lok Sabha election.

${ }^{3}$ Party A: $(1 / 4.4) \times 100=22.7$ and party B: $(3.4 / 4.4) \times 100=77.3$.
} 
1. If $\alpha>1$, then the votes of party A - which is trailing in terms of votes - are amplified or exaggerated in terms of the number of seats by which it trails party B. In other words, the seats ratio, $S_{A}^{t} / S_{B}^{t}$ is smaller than the votes ratio, $V_{A}^{t} / V_{B}^{t}$.

2. If $\alpha<1$, then the votes of party A - which is trailing in terms of votes - are de-amplified or dampened in terms of the in terms of the number of seats by which it trails party B. In other words, the seats ratio, $S_{A}^{t} / S_{B}^{t}$ is larger than the votes ratio, $V_{A}^{t} / V_{B}^{t}$.

3. If $\alpha=1$, then the FPTP system mimics a proportional system: seats are won in the same ratio that votes were obtained.

4. There could be the outcome when parties $\mathrm{A}$ and $\mathrm{B}$ obtain the same number of votes $\left(V_{A}^{t}=V_{B}^{t}\right)$ but win different numbers of seats $\left(S_{A}^{t} \neq S_{B}^{t}\right)$. In this case, the denominator of equation (2) is zero and $\alpha$ will not be defined.

5. There could be the outcome in which party A obtains fewer votes than party B but wins more seats: $V_{A}^{t}<V_{B}^{t}$ but $S_{A}^{t}>S_{B}^{t}$. In this situation the numerator in equation (2) is positive, with the denominator negative, so that $\alpha<0 .{ }^{4}$

Case 5, above, represents the (not unusual) situation where party A obtains a majority in parliament without securing a majority of votes. It is important to point out that since, by assumption, party A trails party B in terms of votes, the smaller the value of $\alpha$, the smaller will be party A's relative disadvantage in terms of seats. When $\alpha=0, S_{A}^{t}=S_{B}^{t}$ with $V_{A}^{t}<V_{B}^{t}$ and when $\alpha<0, S_{A}^{t}>S_{B}^{t}$ with $V_{A}^{t}<V_{B}^{t}$.

\subsection{Calculating the Amplification Coefficient for the INC and the BJP}

We compute the value of the amplification coefficient, from data for eight Lok Sabha elections, held between 1989 and 2014 ( $9^{\text {th }}$ to the $16^{\text {th }}$ Lok Sabha) for the two main protagonists in these elections - the BJP and the INC - by mimicking a two-party system. In the first instance we compare the INC (Party A in the above analysis) with the collective of non-INC parties, including

\footnotetext{
${ }^{4}$ Another perverse outcome would be when party A obtains more votes than party B but wins fewer seats: $V_{A}^{t}>V_{B}^{t}$ but $S_{A}^{t}<S_{B}^{t}$. In this situation the numerator in equation (2) is negative, with the denominator positive, so that $\alpha<0$. This is a situation in which where the party A's majority in votes fails to translate into a parliamentary majority.
} 
Independent candidates (Party B in the above analysis); in the second instance we compare the BJP (Party A in the above analysis) with the collective of non-BJP parties, including Independent candidates (Party B in the above analysis).

$<$ Table 6.3>

Table 6.3 shows that, in 2014, $V_{I N C} / V_{\overparen{I N C}}=0.239$ and $S_{I N C} / S_{\overparen{I N C}}=0.088$ for the INC (where, depending on the context, ${ }^{\wedge}$ over the party name represents 'non-INC' or 'non-BJP'). Consequently, using the expression in equation (6.2), the value of the amplification coefficient, $\alpha$, in the 2014 Lok Sabha elections was 1.7 for the INC and -0.09 for the BJP.

Since $V_{I N C} / V_{\overparen{I N C}}=0.239$ and $S_{I N C} / S_{\overparen{I N C}}=0.088 \Rightarrow\left(V_{I N C} / 0.239\right)=V_{\overparen{I N C}}$ and $\left(S_{I N C} / 0.088\right)=S_{\overparen{I N C}}$, for every vote won by the INC, the non-INC collective won 4.2 votes $(=1 / 0.239)$ but for every seat won by the INC, the non-INC collective won 11.4 seats $(=1 / 0.088)$. On the other hand, for the BJP, $V_{B J P} / V_{\overparen{B J P}}=0.449$ and $S_{B J P} / S_{\overparen{B J P}}=1.08$ meaning that for every vote won by the BJP, the non-BJP collective won 2.2 votes $(=1 / 0.449)$ but for every seat won by the BJP, the non-INC collective won 0.93 seats. ${ }^{5}$ Furthermore, since $V_{I N C} / V_{\overparen{I N C}}=0.239 \Rightarrow V_{I N C}=0.239 \times V_{\overparen{I N C}} \Rightarrow V_{I N C} /\left(V_{I N C}+V_{\overparen{I N C}}\right)=0.239 /(1.239)$, and since $S_{I N C} / S_{\overparen{I N C}}=0.088 \Rightarrow S_{I N C}=0.088 \times S_{\overparen{I N C}} \Rightarrow S_{I N C} /\left(S_{I N C}+S_{\overparen{I N C}}\right)=0.088 /(1.088)$, it follows that in 2014 , the INC received $19.3 \%(=0.239 / 1.239)$ of total votes while winning only $8 \%$ of seats $(=$ $0.088 / 1.088)$ while the BJP, with $31 \%(=0.449 / 1.449)$ of total vote, won $52 \%(=1.08 / 2.08)$ of the seats.

One can verify that the amplification coefficients are correctly calculated by computing the total number seats that a party would have won and comparing these with the numbers actually won: these should be identical if $\alpha$ has been correctly computed. In order to do so, define $\rho=\left(V_{A} / V_{B}\right)^{\hat{\alpha}}$, where $\hat{\alpha}$ represents the value of the amplification coefficient computed using equation (6.2); then, from equation (6.1), the computed number of seats won by party A, is: $\hat{S}_{A}=[\rho /(1+\rho)] \times\left(S_{A}+S_{B}\right)$,

$V_{I N C} / V_{\overparen{I N C}}=0.239 \Rightarrow V_{I N C}=0.239 \times V_{\overparen{I N C}}=0.239 \times V_{\overparen{I N C}}+0.239 \times V_{I N C}-0.239 \times V_{I N C} \Rightarrow V_{I N C} /\left(V_{I N C}+V_{\overparen{I N C}}\right)=0.239 /(1.239)$ This implies that in 2014, the INC received $19.3 \%$ of total votes while winning only $8 \%$ of seats while the BJP, with $31 \%$ of total vote, won $52 \%$ of the seats. For the INC, $[0.239 / 1.239]=0.193$ and ; for the BJP, $[0.449 / 1.449]=0.31$ and $[1.08 / 2.08]=0.52$ 
where $S_{A}+S_{B}$ represent the total number of elected seats in parliament. This should equal, $S_{A}$, the actual number of seats won by party A.

The fact that, in 2014, $\alpha>1$ for the INC reflects the fact that the INC won $19.3 \%$ of the popular vote but only $8 \%$ of Lok Sabha seats: as noted in point 1, above, this means that INC's disadvantage, relative to the non-INC parties, in terms of votes were amplified in terms of seats. The fact that, in the same election, $\alpha<0$ for the BJP reflects the fact that the BJP won a majority in the Lok Sabha without winning a majority of the popularity vote (point 5 , above). ${ }^{6}$

In 2004, the INC's votes and seats ratios were almost equal - respectively, 0.361 and 0.364 yielding a value of the INC amplification coefficient close to unity $(\alpha=0.99)$. This illustrates point 3 above: in the context of the INC, the electoral system yielded a proportional outcome. However, in the same election, $\alpha=0.89$, meaning that the BJP's disadvantage, relative to the non-BJP parties, was dampened with respect to seats.

Remembering that a lower value of $\alpha$ is more desirable than a higher value, Table 6.3 shows that the value of $\alpha$ was smaller for the BJP than the INC for six - 1989, 1996, 1998, 1999, 2004, and 2014 - of the eight elections studied. Equally worryingly for the INC, was that $\alpha>1$ for four of the eight elections between 1989 and 2014. This meant that in the 2014, 1999, 1996, and 1989 elections, the INC vote disadvantage, relative to the non-INC parties, was amplified in terms of a seats disadvantage. For example, in 1999, for every vote won by the INC, the non-INC parties won 2.5 votes but, for every seat won by the INC, the non-INC parties won 3.8 seats.

The BJP did not have this problem: as Table 6.3 shows, in each of the eight elections the value of its amplification coefficient was less than one meaning that is was able to neutralise some of its vote disadvantage, relative to the non-BJP parties, in terms of its seat disadvantage. For example, in 2009 , with $\alpha=0.89$, for every vote won by the BJP, the non-BJP parties won 4.3 votes but, for every seat won by the BJP, the non-BJP parties won 3.7 seats. Thus the essential difference between the BJP and the INC was that, compared to the INC, the BJP was more efficient in translating votes into seats.

\footnotetext{
${ }^{6}$ If the BJP, on a minority vote, had won the same number of seats as the collective of non-BJP parties (that is, 271 or 272 seats), the value of $\alpha$ would have been zero.
} 
In order to understand this measure of this inefficiency consider a party which targets, say, 200 (out of a total of 543) seats in the Lok Sabha. Then, from equation (6.2), the vote ratio which will deliver this is: $V_{A} / V_{B}=\left(S_{A} / S_{B}\right)^{1 / \alpha}=(0.368)^{1 / \alpha}$. Excluding the election of $2014-$ which was a landslide victory for the BJP and, arguably, an outlier on a scale unlikely to be repeated - the average of the amplification coefficient over the seven elections between 1989 and 2009 was 0.96 for the INC and 0.76 for the BJP. Applying these averages, in order to win 200 seats in the Lok Sabha the INC and BJP would have required a vote ratio of, respectively, 0.353 and 0.267 .

In other words, to win 200 seats in the Lok Sabha, the INC would have had to receive 35 votes for every 100 votes received by the collective of non-INC parties (that is, 26 percent of the total vote) but the BJP would have had to receive only 27 votes for every 100 votes received by the collective of non-BJP parties (that is, 21 percent of the total vote). The value of the amplification coefficient, $\alpha$, is thus a measure of electoral efficiency - the smaller its value, the greater the ease with which votes are converted into seats.

\subsection{Hindi Speaking States}

In earlier chapters we had drawn attention to the importance of Hindi-speaking (HS) states to the relative electoral fortunes of the INC and the BJP. To recapitulate: of the total of 543 Lok Sabha constituencies, 204 (or 37.6 percent) are - and have been since the 1996 Lok Sabha election - in the seven Hindi speaking (HS) states of Bihar, Chhattisgarh, Jharkhand, Madhya Pradesh, Rajasthan, Uttarakhand, and Uttar Pradesh and, of these 204 constituencies, respectively, 40 and 80 are in Bihar and Uttar Pradesh. The HS states are of particular importance for the BJP since a large number of its contested constituencies are from these states: in 2014, nearly 45 percent (192 out of 428) of the constituencies contested by the BJP were from the HS states. These states are also important for the INC but to a lesser degree: 34 percent (158 out of 464) of the constituencies contested by the INC in 2014 were from the HS states. We can pursue the analysis of electoral efficiency (meaning the relative ease with which votes are converted into seats) by computing the INC and BJP amplification coefficients for constituencies in the seven Hindi speaking states. 
Table 6.4, which reproduces the all-India results of Table 4.3 for the collective of HS states, shows that the BJP's electoral efficiency was far greater than that of the INC in the HS states. Except for the 2009 election, the INC's seat ratio was always smaller than its vote ratio resulting in an amplification coefficient that was greater than one. By contrast, the BJP's seat ratio was always larger than its vote ratio resulting in an amplification coefficient that was less than one. Indeed, in the 1996, 1998, and 2014 elections, the BJP secured a majority of the Lok Sabha seats from the HS states on a minority vote (point 5 above)

\section{$<$ Table 6.5>}

In contrast, as Table 6.5 shows, the INC performed much better, relative to the BJP, in the non-HS states. Its votes and seats ratios (that is, $V_{I N C} / V_{\overparen{I N C}}$ and $S_{I N C} / S_{\overparen{I N C}}$ ) were both higher in the non-HS states than in the HS states and its amplification coefficient was more favourable: bearing in mind that, as discussed earlier, a lower value of the amplification coefficient is more desirable than a higher value, the amplification coefficient for the INC was always lower in the non-HS, than in the HS, states; conversely, the amplification coefficient for the BJP was always lower in the HS, than in the non-HS, states.

In order to gain an appreciation of differences in inter-party electoral performance between the HS and non-HS states, suppose that the INC and the BJP each target one in three of the seats from the HS states (total 204 constituencies) and a similar proportion from the non-HS states (total 313 constituencies). Excluding the 2014 election, the average of the amplification coefficients over the last three elections $(1999,2004$, and 2009) was, in the HS state, 1.12 for the INC and 0.53 for the BJP and, in the non-HS states, it was 0.93 and 0.95 for, respectively, the INC and the BJP. Then, the vote ratios that would deliver half of the constituencies, in the HS states, to the INC and the BJP are, respectively, $V_{A} / V_{B}=\left(S_{A} / S_{B}\right)^{1 / 1.12}=(0.5)^{1 / 1.12}=0.54$ and $V_{A} / V_{B}=\left(S_{A} / S_{B}\right)^{1 / 0.53}=(0.50)^{1 / 0.53}=0.27$. In other words, to win one-third of the seats in the HS states, the INC and the BJP would have required vote shares of, respectively, $35(=0.54 / 1.54)$ and 21 percent $(=0.27 / 1.27)$ in the HS states. On the other hand, to win one in three seats in the non-HS states, both the INC and the BJP would 
have needed a vote ratio - of, respectively, INC to non-INC votes and BJP to non-BJP votes, of 0.48 or $32(=0.48 / 1.48)$ percent of the vote in the non-HS states. ${ }^{7}$

\subsection{Concluding Remarks}

The contribution of this chapter was to develop the concept of the amplification coefficient which, when applied to the votes received and seats won by a party, could be used to assess its ability to convert votes into seats. In this respect, this chapter's major finding was that the BJP, in electoral terms, was much more efficient than the INC. This can be encapsulated in our finding that, averaging over the eight Lok Sabha elections between 1989 and 2014, in order to win 200 seats in the Lok Sabha the INC would have had to receive 35 votes for every 100 votes received by the collective of non-INC parties (that is, 26 percent of the total vote) but the BJP would have had to receive only 27 votes for every 100 votes received by the collective of non-BJP parties (that is, 21 percent of the total vote).

This places the INC at a considerable disadvantage vis-à-vis the BJP in terms of contesting elections and suggests that this is an issue that the INC's managers could usefully address.

\footnotetext{
${ }^{7}$ Vote ratios of $0.47\left(=(0.5)^{1 / 0.93}\right)$ and $0.48\left(=(0.5)^{1 / 0.95}\right.$ which amounts to 32 percent of the vote in the non-HS states.
} 